\title{
The Effect of Critical Rhetoric in Teaching English as a Foreign Language
}

\author{
Ibrahim Abushihab \\ English Department, Faculty of Arts, Al-Zaytoonah University of Jordan, Jordan
}

\begin{abstract}
The present paper represents an attempt so as to examine and analyze texts in terms of the context and its relation to cultural, political and social issues. It also provides theoretical and practical information which are used in classroom to facilitate learning foreign language. Rhetorical analysis is essential to be used and incorporated into EFL classroom because it is an important field which is not isolated from other disciplines like critical thinking and learning process. Special emphasis is laid upon the role of contrastive rhetoric in facilitating the process of learning foreign languages. Some pedagogical implications for studying L2 correctly and effectively are also tackled. Furthermore, the major role of pragmatics in analyzing the Second and Foreign Language text is also highlighted. This is accomplished within a pedagogical point of view. It is hoped that the paper will be of value to EFL teachers, syllabus designers, applied linguists and specialists in ethnography of communication.
\end{abstract}

Index Terms - contrastive rhetoric, EFL, text structure, rhetoric relations and genres

\section{INTRODUCTION}

Rhetoric is the art of using language and its components to produce effect on the receivers of the text. The information of rhetoric can be sent by someone to another for a given aim in a specific context. Rhetorical information in the text refers to rhetorical organization which a text may provide. Hyland (2006) states that cross- cultural analysis of a text is necessary for those who learn foreign languages because rhetorical aspects of L2 may mislead the foreign language learners as a result of given different writing conventions learned in the L1 culture. Rhetoric is not a field that is isolated from other disciplines like critical reading, discourse analysis and pedagogy. Kubota and Lehner (2014: 5) stresses that "pedagogical recommendations made by traditional contrastive rhetoric focus on awareness raising and explicit teaching of the rhetorical norm with prescriptive exercises". Critical discourse analysis is important in analyzing texts because it focuses not only on the propositional meaning of the text, but it also takes into consideration cultural and ideological aspects of the text.

Critical discourse analysis is concerned with how the text may affect its readers and how they are related and interrelated. Austin (1962),Hurford \& Heasley (1983) and Beaugrande \& Dressler (1986) are some of other scholars who focus and study the way of analyzing texts based on the effect of the text on the reader, taking the context and the cultural issues into consideration.

Rhetorical analysis is a decisive tool in TEFL classroom to teach students to analyze the texts based on critical contrastive rhetoric and critical thinking. Envey and Olcay (1999) assure that the basic elements of communication like genre, audience, purpose, messages and tone are linked with critical thinking which is used in both reading and writing. Kubota and Lehner (2004) consider critical contrastive rhetoric as a tool that encourages teachers and learners to reflect on classroom practices such as comparing and contrasting L1 and L2 cultural and rhetorical patterns of the target language.

The rationale of discourse and text analysis should be analyzed and assessed in the multiple social, political and cultural functions of the text. It is necessary for the text interpreter to take into consideration the socio-cognitive issues that bridge the language use with the social and communicative context.

\section{CRitical Perspectives on Contrastive Rhetoric}

The reader ought to benefit from two types of knowledge in order to read and analyze a text effectively:

a. Knowledge of language.

b. Knowledge of content and formal schemata.

Martinez (1996: 190) calls knowledge of content as a schematic_knowledge. To her, "readers possess schematic knowledge related to the local level of rhetorical organization of discourse structures that is knowledge of how two sentences may be joined by causality, contrast, etc."Rhetorical organization of texts is essential in interpreting such texts successfully. The reader must be aware of rhetorical features or rhetorical ideas stated in the text so that he could have good knowledge about the intention of the writer and the function of the text. Martinez (ibid: 195 - 196) states that "second language reading pedagogy must include not only training in the use of strategies, but information about the significance and outcome of these strategies and their utility (i.e. awareness training)." 
Critical reading is an interactive process which entails different components. Some of which are text, writer, reader, context and rhetorical interpretation. Munby (1978) states that reading is a complex process involving the reader, the text and the writer. Accordingly, it is an interactive process which includes different reading skills. Some of which are:

a. Understanding information when not explicitly stated through making references.

b. Understanding conceptual meaning like cause, result, purpose, reason, condition and contrast.

c. Understanding the communicative value of the text.

d. Interpreting the text by going outside it based on context, background knowledge and cultural aspects.

Analyzing a text via reading is a complex process and a cultural phenomenon because each language has its own rhetorical conventions which are different from others. It is not easy for the reader to touch the intention of the foreign language writer because his intention is based on his own culture which may be unique in comparison to the reader's culture. Kaplan (1966) says that rhetoric deals with what goes on in the mind rather than what comes out of the spoken or written texts. It refers to cultural and rhetoric aspects being essential elements in text analysis. Rhetoric is also a decisive factor in writing process because each writer has his own intention beyond the text which may aim to inform, persuade or convey specific message and the good reader must have a good ability to touch and find it.

According to Chien (2007) there are differences between texts written by speakers of different languages and members of different cultures. This gives insights that contrastive rhetoric provides how culture-bound thought patterns are used in EFL texts. If the text is easily analyzed, it must be produced to conform to the conventions of the readers and to meet their expectations which are based on cultural aspects.

\section{GENRE AND TEXT TYPES}

The configuration of ideas in a text and its formal structure usually gives hints of its genre. For example, a newspaper has different parts. One of which is advertisement. Its genre is known by its title. The concept of genre focuses on the relation between the structure of the text and its function in cultural context. It also includes the communicative events of the text.

The text whether spoken or written has been produced with specific conventions which can be used to specify the type of a text. Such conventions have two genres:

a. No-fiction: The types of the texts which are categorized under this genre are news report, biographies, textbooks, journals, documentaries, advertisements, etc.

b. Fiction: The types of the texts which are categorized under fiction are movies, poems, plays, novels, songs, lyrics, short stories, etc.

In addition to non-fictional and fictional texts, there are two categories of texts. First, formal typology which focuses on propositional content of the text. It is possible to categorize all literary genres "literary texts" in this type. It includes poetry, drama, short story, novel, etc. This type focuses on a major difficulty which is the problem of the definition of the types belong to it. For example, it is not easy to answer the question of what is meant by poetry because it deals with poet's treatment of the topic that makes it poetic. The problem is how such treatment is interpreted by the reader and the linguistic characteristics of poetry being different from non-poetry texts. Second, functional typology which focuses on the following major principles:

1- The producer.

2- The subject - matter.

3- The receiver.

Here, we can apply the two types: "formal typology and functional typology" as the following examples show:

\section{Text A:}

In our office, the same budget had been in operation since the nineteen twenties, that is, since a time when most of us were struggling with geography and fractions. Our chief, however, remembered the great event, and sometimes, when there wasn't so much work, he would sit down familiarly on one of our desks, and there, with his legs dangling, and immaculate white socks showing below his trousers, he would tell us with all his old feeling and with his usual five hundred and ninety-eight words, of that distant and splendid day when his chief-he was a Head clerk then-had patted him on, the shoulder and said: "My boy, we're having a new budget. "The budge by Mario Benedetti: 33 - 37"

The above text is categorized under the formal typology because it is an initial paragraph of a short story entitled "The budget". It belongs to the class of literary texts. In terms of function, it is an expressive text with a poetic function. The extracted text focuses on the producer because the narrator of the text belongs to a group working together in an office. His aim is to describe their situation in the government office and their ambition for a new budget which leads to salary raise. Such fictional narrative text (short story) belongs to the category of formal and functional text typology.

\section{Text B}

One hundred and fifty years ago in 1825, when he was only 16 years old, Louise Braille, a blind French student brought enlightenment to the blind. He developed the raised dot Braille system of writing which has become the principal method of reading, and written communication for blind people. "Mackin, et al: $8-11$ "

Text B above is also a formal typology which belongs to the class of academic texts "an essay". In terms of function, it is an informative text with a metalinguistic function. The focus of this essay is on the subject- matter. It offers new 
information to the readers. Unlike the first text, the narrator of the essay is the third person. Most of non-fictional narrative texts such as essays belong to the category of formal and functional text typology.

\section{SOCIO-RHETORICAL INTERPRETATION}

Socio-rhetorical interpretation focuses on analyzing the social and cultural texts. It also provides the interpreter with the techniques so as to analyze and understand the intention of the writer or the speaker. During the last three decades, text analysis focused on linguistic issues. Socio-rhetorical issues which are essential in analyzing texts were ignored. Nowadays, analyzing texts is based on socio-rhetorical variables like intention of the writer and the contexts surrounding texts. Martinez (1996: 195)states that "in order to exploit the rhetorical organization of the texts as a resource for readers to improve their comprehension, this exploitation must be based on making readers aware of and capable of interpreting the rhetorical features or rhetorical information of texts." Writing is an important skill in any language because it is a cultural and rhetorical process. Each writer has different social thought issues that are reflected and organized in writing.

The role of the reader is to find these issues and to analyze them correctly. Kaplan (1966) goes line by line with this trend. He assures that the organization of ideas in a text is shaped by socio rhetorical and cultural patterns.

The interpretation of foreign text is based on the rhetoric of the reader's first language. Accordingly, the readers of the foreign texts may impose his native language cultural competence on the foreign texts which leads to misinterpretation of the text. Thus, the reader of L2 text must be aware of rhetorical cultural patterns of the foreign language so that he could interpret the text successfully. To facilitate interpreting L2 texts in classrooms, contrastive rhetoric is used. It offers the differences and similarities between texts written by writers of different languages which belong to different cultures. Kaplan (ibid) assures that contrastive rhetoric is beneficial in EFL students' writing because it offers essential hints about different cultures which facilitate interpreting EFL texts.

The successful technique of interpreting foreign texts is to be produced in a way that conforms to the cultures of the native readers so that the good readers must bridge the gap between cultural differences. Chien (2007: 146) remarks that "contrastive rhetoric has a lot to offer to teachers and students. Firstly, it explains patterns of writing in different languages and cultures. Secondly, gaining cultural competence will allow for understanding of similarities and differences that will lessen miscommunication and misunderstanding, and increase cultural insight."

To conclude, contrastive rhetoric is essential in facilitating learning foreign languages. It gives some pedagogical implications for studying L2 written texts and dealing with them correctly and effectively.

\section{PRAgMatics And TEXT InTERPRETATION}

Pragmatics is a branch of linguistics which mainly focuses on the principles of language use, the interactions between the reader, writer and the context where the text is said. Abushihab (2015: 120) points out that "pragmatics focuses on the communicative use of language conceived as intentional human action. "Intention" has become the focus of various disciplines; for instance, psychologists study the text producer's intention to guide consciousness of the learner." Pragmatics and text analysis are related and interrelated because pragmatic theory deals with speech act theory and it focuses on the cultural differences in human interaction. The pragmatic theory categorizes speech acts into three types: the first is locutionary speech act which includes several orders of action and events and ideas stated in the text. The second is illocutionary speech act or what is called communicative acts. It consists of the intention of the writer and purpose of the text. The last type is perlocutionary act which deals with the effect of the text on the reader and the consequences of illocutionary act (Austin, 1962, Van Dijk, 1977, Hurford and Heasley, 1983 and Beaugrande and Dressler, 1986).

Pragmatic theory and text interpretation are based on text and context. Halliday and Hassan (1989) remark that text is a functional language not isolated sentences. It is a product, an output, interactive process and a social exchange of meanings. Context is considered as a link between the text and the situation it occurs in. Buja (2010: 260) defines context as "a term referring to the features of the non-linguistic world in relation to which linguistic units are systematically used. In discourse analysis, we encounter the situational context, which, in its broadest sense, covers the total non-linguistic background to a text/ utterance, including the immediate situation in which it is used."

Text interpretation also focuses on bridging between the language and its context. Accordingly, a text produced in a language can be interpreted in terms of interaction of language and its social context.

To interpret the text effectively, we will take into consideration the principles of language use, the interaction between the producers (speaker, writer), the receivers (hearer, reader) and the place (context). Saez (2004: 2) assures that "the analyses of the text took into account the addresser's implications and the addressee's possible inferences in the construction of the argumentative structures of the texts."

As stated above, language and its components are based on context because communication via language requires a good knowledge of the communicative context. Effective communication focuses on having social knowledge, function of the text and the conversational context.

There are five major components of language. One of which is pragmatics which refers to the way language is used in the social context. Auer (1996: 16) states that "five dimensions of context suggest themselves: (a) linguistic contexts 
(sometimes called co-text), (b) non- linguistic sense-data in the surroundings of the linguistic activity (the situation in a physical sense), (c) features of the social situation, (d) features of participants' common background knowledge."

\section{Pedagogical Implications}

Critical contrastive rhetoric is essential in proposing different teaching techniques for helping students study English as a foreign language. It is also necessary in understanding the contrastive rhetoric between the native language and the foreign language. Casanave (2004) points out that contrastive rhetoric helps learners build cultural competence about different conventions of writing. The rhetorical differences between L1 and L2 affect positively L2 writing process. It helps in organizing and composing conventions and making the text cohesive and coherent.

Studying and analyzing a text within the principles of linguistic theory need a full understanding of different aspects of interpretation like structures of sentences, sequences of propositions and the context where the text is said. Mey (1979: 23) states different linguistic understanding levels. Some of which are:

1- Understanding syntactic level of the text and its cohesion.

2- Understanding the propositions of the text beyond the literal meaning.

3- Understanding the sense, the reference and the ambiguities of the text.

A learner must be in contact with a foreign language so that he could find the areas of similarities and differences between L1 and L2.This will facilitate learning the foreign language. Lida (2012: 121) goes side by side with this trend. He remarks that "those elements that are similar to the learner's native language will help facilitate language learning and production and those that are different will affect the writer's production and reproduction."A teacher who has made a comparison of a foreign language with the native language will help the student know better what the real problem are and can provide a better solution for him. Hinds (1987) states that unlike English texts, Japanese texts are interpreted easily because this doesn't require any cognitive effort as the cultural and linguistic knowledge are shared by the reader and the writer.

Critical discourse analysis is an effective tool for teaching composition. It is used in writing course when students are asked to read and analyze a text critically. As stated above, it is not easy for students to analyze a text without taking into consideration the contextual knowledge. This will facilitate the process of analyzing the text and writing about it. This process may be applied in news reports and advertisements. The teacher may develop this process by asking his students to compare and contrast between two different news reports which carry different ideas and different viewpoints. Students impose their own ideas and comments about the texts. Huckin (1997) states that students are asked to analyze the text critically. They are asked to read the text as typical readers in mind. They mostly work in groups. Each one analyzes a text critically and the leader of the group presents the analysis of the text to the whole class. Then, each student writes about the text.

\section{CONCLUSIONS}

Contrastive rhetoric is based on context to find the intention of the writer, so the reader looks beyond the text in order to know how it is produced and analyzed. Language is mainly used to convey messages via a text. It is a means of facilitating the exchange of ideas among people. It may give direct meaning which is easily understood like the word 'stop' that is used as a traffic sign. Language may also be as a challenge. In this case, the writer will give his efforts to fill in the gap and find the missing information. Animal farm is a symbolic novel. It is not easy for the reader to interpret its events unless he knows the context where it was produced and to know the background knowledge of the writer, so he touches the intention of George Orwell who was against the communism.

Socio-cultural analysis starts with the interpretation of social and cultural aspects of written works. Robbins (2004: 44) states that "socio-rhetorical interpreters still face major challenges of analyzing and interpreting prophetic, precreation and priestly rhetorolect in early Christian writings". Aertselaer(2006: 70) remarks that "most of the errors remaining in the academic writing of advanced English philology students are those that concern rhetorical aspects which have two underlying sources for problems in constructing authorial voice: the transfer of typological and rhetorical conventions from the L1."

\section{REFERENCES}

[1] Abushihab, I. (2015). A Pragmatic Stylistic Framework for Text Analysis, International Journal of Education, Vol. 7, No. 1: $119-127$.

[2] Aertselaer, J. (2006). A Rhetorical Analysis Approach to English for Academic Purposes, Revista de Lingustica Y Lenguas Aplicadas, Vol. 1:63-72.

[3] Auer, P. (1996). From Context to Contextualization, Links and Letters, 3: 11 - 28.

[4] Austin, J. (1962). How to do Things with Words, London: OUP.

[5] Beaugrande, R. and W. U. Dressler. (1986). Introduction to Text Linguistics, London: Longman.

[6] Benedetti, Mario. (1978). The Budget in Oxford Secondary English Course Jordan: Anthology Three, London: OUP: 33 - 37.

[7] Buja, E. (2010). The Discourse Analysis of a Newspaper Article, Acta Universitatis Sapientiae, Philologica, 2, 2: 259 - 271.

[8] Casanave, C. (2004). Controversies in Second Language Writing: Dilemmas and Decisions in Research and Instructions, Ann Arbor: University of Michigan Press. 
[9] Chien, S. (2007). The Role of Chinese EFL Learners' Rhetorical Strategy Use in Relation to their Achievement in English Writing, English Teaching Practice and Critique, Vol. 6, No.1: 132 - 150.

[10] Eney, M. and S. Olcay. (1999). How to Use Rhetorical Analysis in the Classroom in $3^{\text {rd }}$ International Inged-Gazi ELT Conference Proceedings, Gazi University, Ankara, 121 - 127.

[11] Halliday and Hassan. (1989). Language, Context and Text, London: OUP.

[12] Hinds, J. (1987). Reader versus Writer Responsibility: A New Typology. In U. Corner and R. B Kaplan (Eds.) Writing across Language: Analysis of L2 Text (PP. 141 - 152). Reading ,MA: Addison. Wesley Publishing Company.

[13] Huckin, T. (1997). "Critical Discourse Analysis" in T. Miller (ed.) Functional Approaches to Written Text: Classroom Application. Washington D. C: United States information Agency: 78 - 92.

[14] Hurford and Heaslay. (1983). Semantics: A Course book, Cambridge: CUP.

[15] Hyland, K. (2006). English for Academic Purposes: An Advanced Resource Book, London: Routledge.

[16] Kaplan, R. (1966). Cultural thought Patterns in Intercultural Education, Language Learning. 16 (1): 1 - 20.

[17] Kubota, R. and Lehner, A. (2004). Towards Critical Contrastive Rhetoric, Journal of Second Language Writing, $13: 7$ - 27.

[18] Lida, Liu. (2012). A Contrastive Analysis of Repetition Strategies Employed in Chinese EFL Writing and Chinese-English Translation, Intercultural Communication Studies, XX 12: 111 - 130.

[19] Mackin, R. et all. (1978). Knowledge at their Fingertips in Oxford Secondary English Course, Jordan: Anthology Three, London, OUP.

[20] Martinez, A. C. (1996). The Exploitation of the Rhetorical Structures of the Text to improve ESP Reading Comprehension, Revista de Lenguas Para Fine Especificos, No. 3; 188 - 197.

[21] Mey, J. (1979). Pragmalinguistics The Hague: Mouton.

[22] Munby, J. (1978). Communicative Syllabus Design, Cambridge: CUP.

[23] Robbins, V. (2004). Beginnings and Developments in Socio-Rhetorical Interpretation, Emory University, Atlanta, GA, USA: 1 $-44$.

[24] Saez, N. (2004). The Pragmatic and Argumentative Structures Underlying English Written Advertisements, Anuario de Pregrado: 1 - 17.

[25] Van Dijk, T. A. (1977). Text and Context: Explorations in the Semantics and Pragmatics of Discourse, London: Longman.

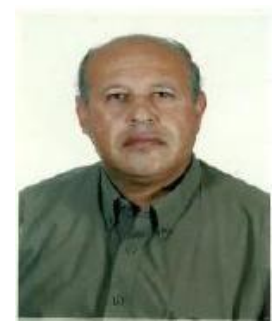

Ibrahim Mohammad Abushihab was born in Jordan 1958. He got his BA in English and MA in TEFL from Yarmouk University/Jordan (1986), whereas PhD degree in Applied Linguistics was received from Gazi University/Turkey (2003). Over the past 30 years he has been teaching English as a foreign language to Arab students in the Ministry of Education in Jordan, Aljouf University (Saudi Arabia) and Alzaytoonah Private University of Jordan. Since then, he has been doing research in the field of Linguistics, Discourse Analysis, Stylistics, Applied Linguistics and Contrastive Analysis. Dr. Ibrahim Abushihab is a Professor of Applied Linguistics at Alzaytoonah University of Jordan. 